Article

\title{
Temporal Changes of Per Capita Green Space of Colombo District, Sri Lanka
}

\author{
Li Lin ${ }^{1,2,3^{*}}$ and PGRNI Pussella $a^{1,2,3,4}$ \\ 1 School of Resources and Environmental Science, Wuhan University, 129 Luoyu Road, Wuhan 430079, \\ China; lilin@whu.edu.cn \\ 2 Collaborative Innovation Center of Geo Spatial Technology, Wuhan University, 129 Luoyu Road, Wuhan \\ 430079, China; lilin@whu.edu.cn \\ 3 The Key Laboratory of Geographical Information System, Ministry of Education, Wuhan University, 129 \\ Luoyu Road, Wuhan 430079, China; lilin@whu.edu.cn \\ 4 Department of Remote Sensing \& GIS, Faculty of Geomatics, Sbaragamuwa University, PO Box 02, \\ Belihuloya, Sri Lanka; pgrnip@geo.sab.ac.lk \\ * Correspondence: lilin@whu.edu.cn; Tel.: +86-138-7150-4963
}

\begin{abstract}
Green spaces take part a vital role in reducing the harmful effects occurred through the process of rapid urbanization. This study focuses on evaluating the change of green space and per capita green space in Colombo District, Sri Lanka in between 2008 and 2015 using Landsat images. The NDVI differencing method and classification method were used to detect the change of land cover. According to the results, a gradual decline of green space from $629.1 \mathrm{~km}^{2}$ to $591.16 \mathrm{~km}^{2}$ with a rate of $6.03 \%$ can be depicted. The change is considerable in Kaduwela, Moratuwa and Maharagama DSDs and quite better in the areas such as Avissawella, Homagama and Padukka. The per capita green space has been decreased from $272.361 \mathrm{~m}^{2}$ to $248.811 \mathrm{~m}^{2}$. Though these rates are very well higher than the UN, EU and WHO standards for the district, Colombo DSD do not comply with UN and EU standards. The case would turn into worst in 2025, as the predictions with current rates. Therefore, the study recommends taking immediate actions to make a greener city. Further, a tax system is proposed to get the attraction of the general public.
\end{abstract}

Keywords: Green Space, NDVI, Per Capita, Urbanization

\section{Introduction}

Rapid urbanization is a common problem everywhere in the developing countries [1]. The most of the people search their dwellings in cities because of the numerous infra-structure facilities in the city environments or its suburbs to fulfill their needs. As a result of that, cities are expanding by human settlements of permanent and temporary residents and development activities. Currently this has been converted into a worst scenario and brings some bad consequences. According to the United Nations (UN) estimations, the urban population would be increased to $61.1 \%$ (5.6 billion) of the global population in 2025 which was $37.7 \%$ (1.58 billion) in 1975 with the global annual average growth of $2.38 \%$ [2]. But these rates could be changed and would be much higher, specially, in the case of developing countries [2]. The rapid growth of urban population would lead to utilize remaining greener areas in the city for different purposes or expansion the periphery of the city extensively. As a result of this, the size of the urban green space decreases at an alarming rate. Urban green spaces are more significant in reducing the negative impacts of rapid urbanization [3]. Therefore, green spaces are also called as green lungs of a city. These spaces are acting as a part of city landscape and the urban planners must pay their special attention to keep and maintain a considerable portion of the green area in the process of planning cities [4]. And also green spaces are becoming a significant method for evaluating the environmental quality and the ecological sustainability of urban areas [5]. The degradation of green space is very harmful for the human health [6] and it reduces the 
biodiversity badly, destroy the habitats for animals [7]. Finally it would effect for the process of entire ecosystem in the natural environment.

Green spaces perform a number of functions such as controlling the surrounding temperature, increase the relative humidity, absorbing carbon-dioxide and producing oxygen, optimizing the hydrological conditions, reducing the noise pollution, providing shadows and creating new habitats for some animals and creation of a beautiful landscape [8]. Furthermore, economically, they help to improve the condition of living of urban dwellings through increasing property values and reducing the consumption of energy for cooling [9]. These functions would reduce the negative impacts of concrete developments in the city into some extent. Therefore, it is very important to allocate a considerable portion of the city area for green spaces almost in all cities in the city planning processes. Since the extent which has been allocated for green spaces in a city is very important, it uses as an indicator to measure the environmental quality of the city. One of the indicators is per capita green space. To calculate the value for the indicator, the extent of the area covered by the green spaces should be divided by the population of that area [10]. This value represents the extent of the green area in square meters $\left(\mathrm{m}^{2}\right)$ for a single citizen. Different organizations and institutions have expressed the minimum limits for per capita green space, UN expressed the per capita green space should be more than $30 \mathrm{~m}^{2}$, European Union (EU) says it has to be over $26 \mathrm{~m}^{2}$, while the World Health Organization (WHO) recommends it should be more than $9 \mathrm{~m}^{2}[11]$. In the present study, the per capita green space was used to assess the quality of the environments of DSDs in Colombo district as the main objective.

Colombo district is the heart of the country and is very important for the social, economical and cultural stability. It is situated in the Western province of Sri Lanka and approximately covers 682 $\mathrm{Km}^{2}$ of land with a population of 2.33 millions in 2015 [12]. Colombo district is consisted with 13 Divisional Secretariat Divisions (DSDs): Colombo, Kolonnawa, Thibirigasyaya, Kaduwela, Sri Jayawadenapura Kotte, Dehiwala, Maharagama, Moratuwa, Rathmalana, Kesbewa, Homagama, Avissawella, and Padukka as local authorities for administration purposes (Figure 1).

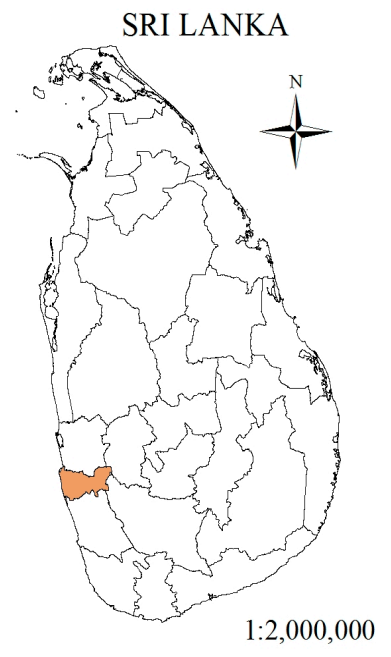

(a)

\section{COLOMBO DISTRICT DS DIVISIONS MAP}

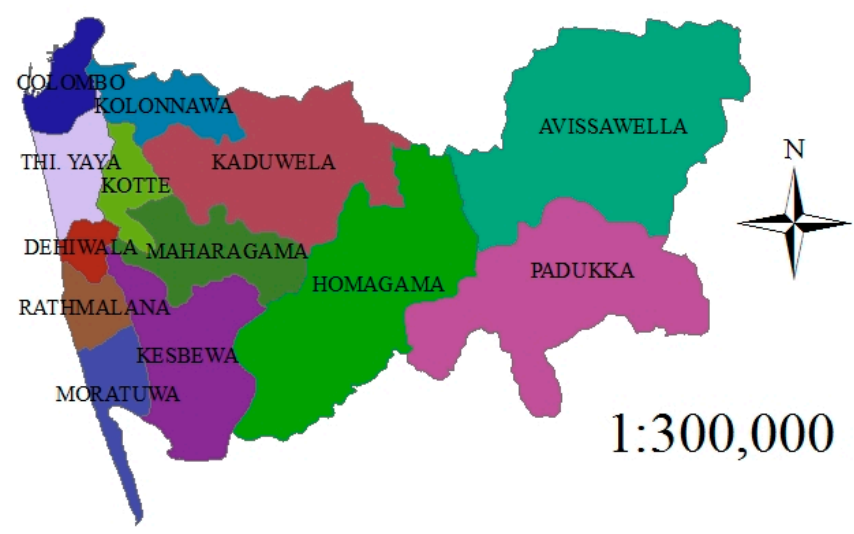

(b)

Figure 1. Study Area: (a) Sri Lanka Map; (b) Colombo District DSD Map

During the recent past years, many development activities have been carried out in Sri Lanka, specially, in Colombo district. It has led severe changes in the land cover. But there is no recent comprehensive study to analyze how the green space has changed and how it has influenced to the human and environmental conditions. Therefore, this study is significant, since this is the first attempt to find out the temporal changes of green space quantitatively and calculate the per capita green space of each municipal councils of Colombo district using the integrated method of Remote Sensing and Geographical Information Systems (GIS). Further, the study predicts the per capita green 
space values for year 2025 with the current rate of the population growth and reduction of green space as a sub objective of the study. Finally, it would find out the areas which do not comply with the standards defined by the UN, EU and WHO for future decision making processes.

\section{Materials and Methods}

There are different methods to detect the changes in the land cover. According to the purpose of the study, the method can be selected. In this study, an integrated technique of remote sensing and GIS was used. Remote sensing integrated with GIS provides an excellent platform to detect, monitor and manage different types of land related problems by presenting effective and efficient solutions. It is a well known tool in the process of detecting changes of an object or a phenomenon based on the images which were taken at different time intervals [13]. This would be affected by the elements such as spatial constraints, spectral constraints, thematic constraints and temporal constraints, atmospheric conditions and soil moisture conditions [14]. In any remote sensing based change detection technique, it would compare the difference between the spectral responses of two or more pixels of same ground coverage which have been taken on two days [14].

Different change detection techniques such as comparison of land cover classifications, image differencing, image rationing, vegetation index differencing, principal components analysis and change vector analysis, have been introduced, specially, for land cover changes [14]. These various techniques give different outputs. For an example, image differing method provides binary information about the change by providing the results as change or no-change [15]. If the study needs further details about the change, a post classification technique must be applied [16]. It means that selection of the appropriate technique for a specific task is a challenge.

In this study, the vegetation index differencing technique was used to identify the changes. The vegetation indices are associated with the phenomenon of vegetation. This is the most widely used index for remote sensing in the past two decades to detect the vegetation change [17]. It is very simple and quick method to detect the vegetated areas and their conditions. The NDVI values vary from -1 to +1 . Non vegetation areas would get a below zero value and dense forest canopies would have +1 as the NDVI value, while bare soil areas would be represented by a value closed to 0 [17].

The methodology of this study consists with several steps to achieve the objectives (Figure 2). Firstly, the Landsat TM image acquired on 04.11.2008 and Landsat ETM+ image on the date of 14.04.2015 were downloaded from USGS (United State Geological Survey) Earth Explore web site in GeoTIFF file format, were pre processed to correct the geometric, radiometric and atmospheric errors. Population data of DSDs of Colombo district were obtained from the official web site of Department of Census and Statistics of Sri Lanka. District shape files with DSD boundaries and land cover maps were taken from the Survey Department of Sri Lanka. 


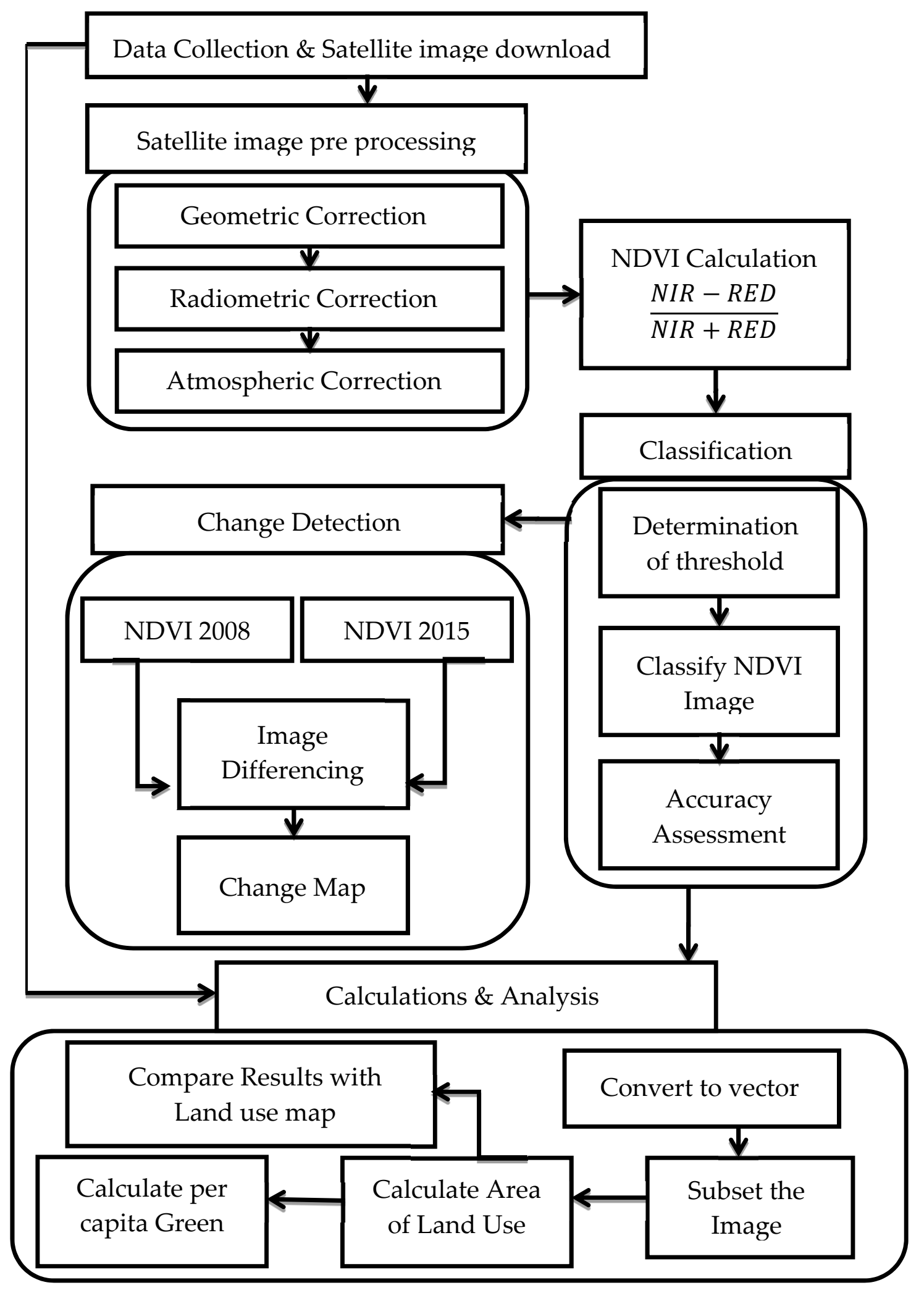

Figure 2. Methodology

NDVI image for values were calculated as the second step. Satellite images data provides information on vegetation structure and amount of biomass. This vegetation cover area can be estimated though various indices. NDVI method is one of the widely used vegetation index. In the ERDAS IMAGINE software environment, the NDVI image was prepared. The NDVI value can be considered as (NIR - RED)/ (NIR + RED) where NIR - Near Infra Red band value for a cell and RED - Red band value for the cell [17]. This value would be always in between -1 and +1 , where negative 
values represent no vegetated areas, around zero values represent bare soil and rock areas and positive values correspond to vegetated areas [18]. If the vegetation is in good health, the NDVI value would be +1 . The two-dated NDVI images were classified into three classes (Green space, Soil/building/road and Water) by using the NDVI threshold ranges technique.

In this study, threshold values for classification of the image were determined by selecting sample points for each land use classes and comparing NDVI value correspond to those points (Figure 3). Thus threshold values for each satellite images were determined separately. The results indicated that NDVI values for green spaces would fall in between 0.3 and 1 ; values for soil/building/road ranged in between 0 and 0.229 , while water areas are represented by the values less than 0 of Landsat ETM+ image of year 2015. Similarly, in the Landsat TM image of the year 2008, NDVI values lesser than 0.015 represent water bodies, values in between 0.220 and 0.016 represents soil/building/road areas and green spaces would be represented by the values greater than 0.221 .

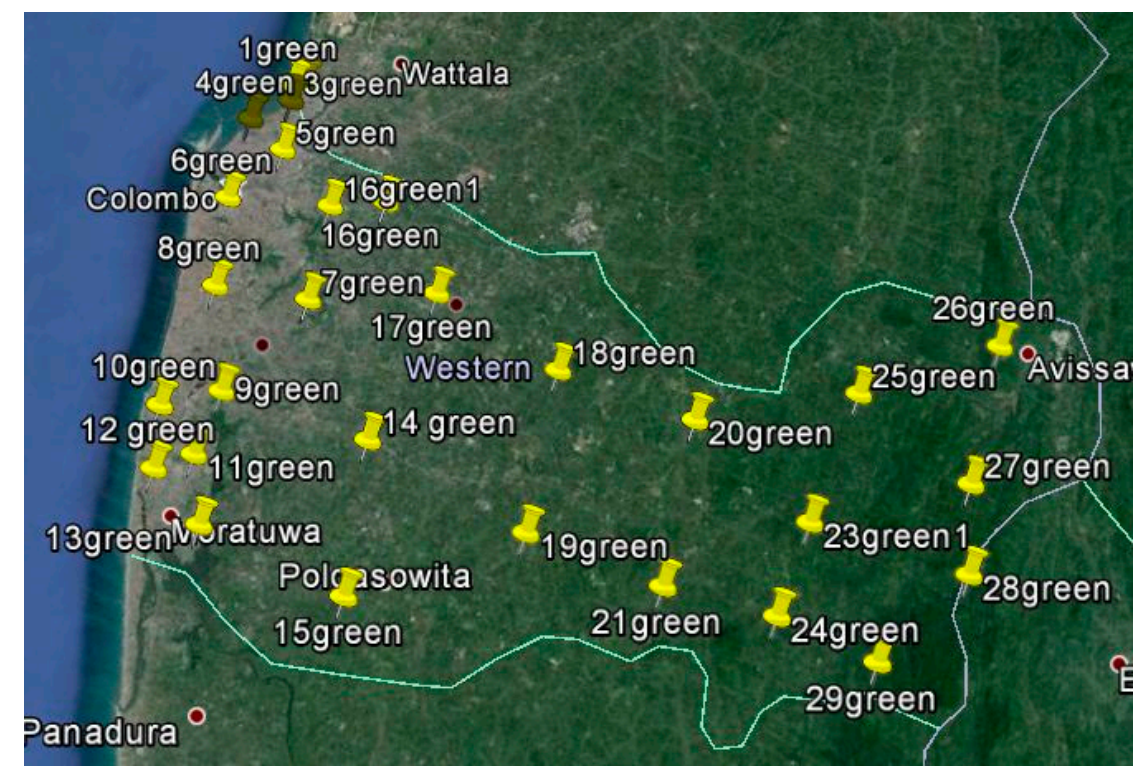

Figure 3. Ground sample points, used to determine threshold values

By using the accuracy assessment which was done based on the ground truth points, the classification results were evaluated. The results of this would be represented by a classification error matrix. It would compare the results of the classification process and the real land cover for a number of sample points. Google earth images, true and false color composite images and prior knowledge about the area were used as reference data in this. The accurate assessment of the resulted land cover maps would include 500 random truth points to calculate the error probability of each map. The accuracy assessment was carried out using ArcGIS software. Firstly, ground truth points shape file was created and then using the tool "extract values to points", it was compared the ground truth points with classified data. The "frequency" tool was used to find how many ground truth points had been classified to each class. Then error matrix was created using "pivot table" tool in ArcGIS. Finally using the above error matrix, user's accuracy, producer's accuracy and overall accuracy were calculated.

Automated methods of remote sensing change detection usually are of two forms: postclassification change detection and image differencing using band ratios. In post classification change detection, the images from each time period are classified using the same classification scheme into a number of discrete categories (i.e., land cover types). The two (or more) classifications are compared and the area that is classified the same or different is tallied. With image differencing, a band ratio such as NDVI is constructed from each input image, and the difference is taken between the band 
ratios of different times. In the case of differencing NDVI images, positive output values may indicate an increase in vegetation, negative values for a decrease in vegetation, and values near zero means there is no change. In the present study, image differencing method was used to obtain the change detection by using "change detection" tool in ArcGIS.

Both classified images were converted to vector format, so that they can be analyzed in the ArcGIS environment. With the use of Colombo district shape file vectorized images were clipped and area related to each land-use class of both years was calculated using calculate Geometry function. Then the per capita green space was calculated using the population data. The results were compared with the land use map of the Colombo district which is prepared by the Survey Department of Sri Lanka. The land use classes which were having LU_GFCODE (land use code) as CCNTA (coconut), CHENA (chena), FRSUA (forest), HOMSA (home gardens), MRSHA (marshy), PDDYA (paddy), RBBRA (rubber), SCRBA (scrub), TEAA (tea) were selected as green space. Areas having LU_GFCODE as LAKEA (lake), BAYA (bay), RSVRA (reservoir), SEAA (sea), STRMA (stream), TANKA (tank), WTRHA (water) were taken as water areas. And SANDA (sand), APRTA (apartments) and BLTPA (built up area) of LU_GFCODE were selected as Soil/Building/Road areas.

\section{Results}

The result of this process was a set of 8-bit gray scale NDVI images representing the amount of green space for two years. Examining the gray scale of the NDVI for each year was a visually simplistic way to analyze the progression of green space. The Figure 4, healthy vegetated areas can be identified in white colour and areas where there is no vegetation can be seen in gray colour. And also, areas where no vegetation exists can be visually identified in black. The white area has stronger near-infrared reflectance and this represents that most of the visible light was used for product biomass by producing NDVI values ranging between 0.221 and 1 in 2008 image and 0.3 and 1 in 2015 image. Further, negative NDVI values were shown in the dark areas indicating regions of typical water, cloud, bare soil, buildings and rock.

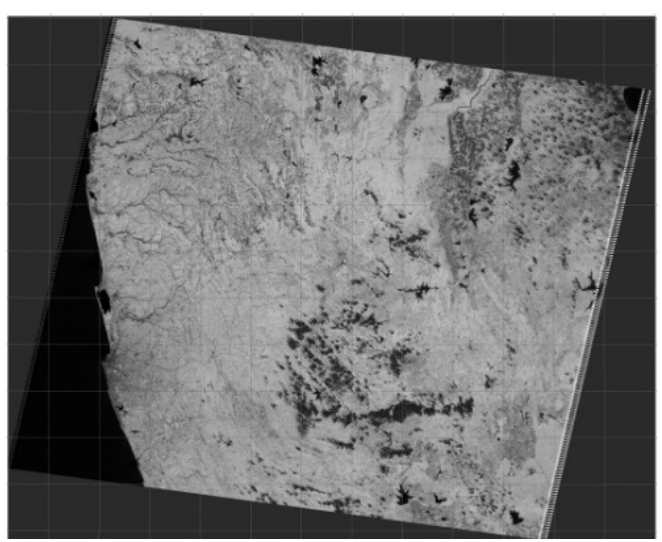

(a)

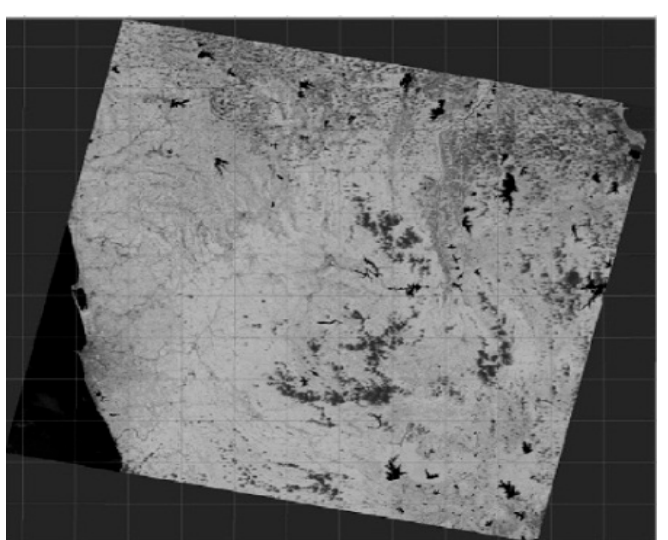

(b)

Figure 4. NDVI Images in Gray Colour: (a) in 2008; (b) in 2015.

The NDVI images in colour table are shown in Figure 5 for two different years. 


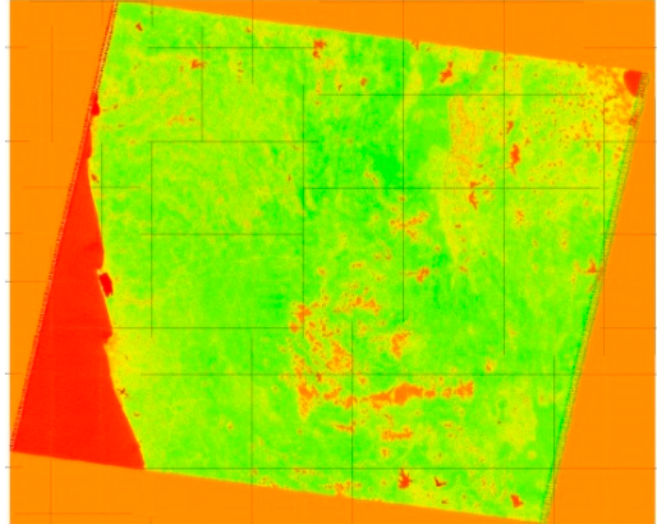

(a)

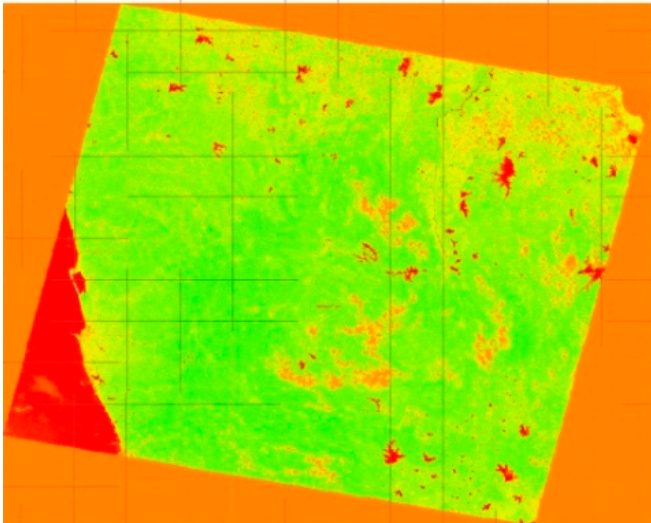

(b)

Figure 5. NDVI Images in Colour Table: (a) in 2008; (b) in 2015

In this study, the NDVI values were divided into 3 main classes: Water, Soil/Building/Road and Green space. The classified maps were prepared for two years as shown in Figure 6. since the accuracy assessment is very important and it was done using error matrix on the land cover maps which is tabulated in Table 1 and Table 2 for 2008 and 2015 respectively. It is found that, the overall accuracy obtained using ArcGIS for 2008 is $88.33 \%$, while in the year 2015, 91.67\% were calculated as shown in Table 1 and Table 2. In addition, the user's accuracies for both years for all classes exceeded $82 \%$ and $86 \%$ respectively, furthermore; the producer's accuracy (2008) exceeded $90 \%$ of all the classes except for water areas while it is $84 \%$ in 2015. This implies that the classification was done with the highest accuracy using the 120 ground truth points.

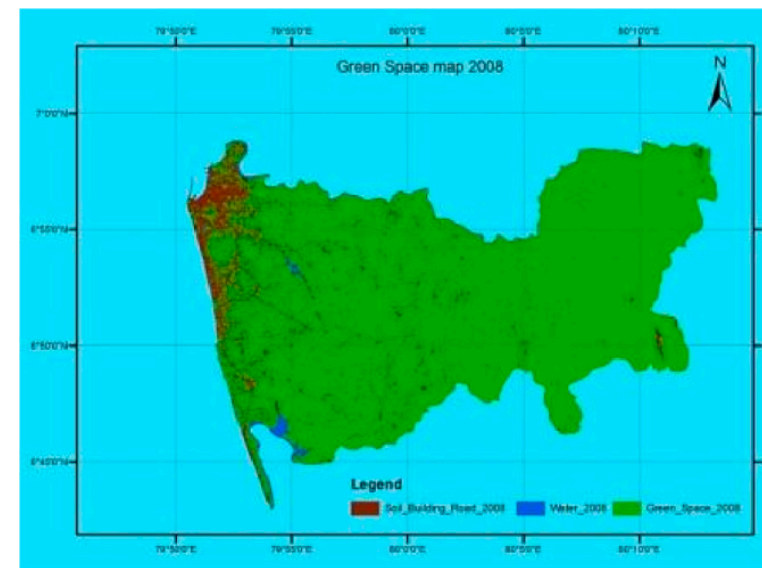

(a)

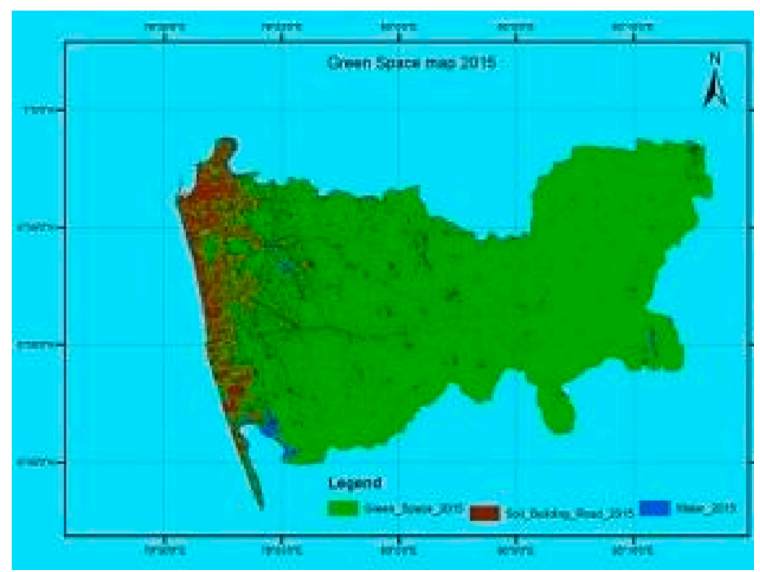

(b)

Figure 6. Green Space Map: (a) in 2008; (b) in 2015

Table 1. Accuracy Assessment for Image of 2008.

\begin{tabular}{ccccccc}
\hline Class Name & Predicts & Truth 01 & Truth 02 & Truth 03 & $\begin{array}{c}\text { User's } \\
\text { Accuracy }\end{array}$ & Predicts \\
\hline Water & 01 & 31 & 00 & 00 & $100 \%$ & 31 \\
Soil/ Building/ Road & 2 & 7 & 37 & 1 & $82.22 \%$ & 45 \\
Green Space & 3 & 3 & 3 & 38 & $86.36 \%$ & 44 \\
& $\begin{array}{c}\text { Producer's } \\
\text { Accuracy } \\
\text { Count }\end{array}$ & $75.61 \%$ & $92.50 \%$ & $97.44 \%$ & $88.33 \%$ & \\
& Truth & 41 & 40 & 39 & & 120 \\
\hline
\end{tabular}


Table 2. Accuracy Assessment for Image of 2015.

\begin{tabular}{ccccccc}
\hline Class Name & Predicts & Truth 01 & Truth 02 & Truth 03 & $\begin{array}{c}\text { User's } \\
\text { Accuracy }\end{array}$ & Predicts \\
\hline Water & 1 & 44 & 3 & 0 & $93.62 \%$ & 47 \\
Soil/ Building/ Road & 2 & 1 & 27 & 0 & $96.43 \%$ & 28 \\
Green Space & 3 & 4 & 2 & 39 & $86.67 \%$ & 45 \\
& $\begin{array}{c}\text { Producer's } \\
\text { Accuracy }\end{array}$ & $90 \%$ & $84 \%$ & $100 \%$ & $91.67 \%$ & \\
& Count & 49 & 32 & 39 & & 120 \\
\hline
\end{tabular}

The table 3 shows the total area and percentage changes of the green space from 2008 to 2015 for each and every DS Divisions in Colombo District. The results show that the total extent covered by green space of $629.1 \mathrm{~km}^{2}$ in 2008 has decreased to $591.16 \mathrm{~km}^{2}$ in 2015 . It means that the extent of green space in Colombo district has been decreased by $37.94 \mathrm{~km}^{2}$ with a ratio of $6.03 \%$ for a period of 07 years. Further it can be noticed that the change is remarkable in Kaduwela, Moratuwa and Maharagama DSDs. When the percentage change is being considered, it can be observed significant changes in Dehiwala, Moratuwa, Rathmalana, Thimbirigasyaya and Colombo areas. According to the Figure 06, it can be observed that the rapid urbanization and infra structure development has not influenced much for the green spaces in, comparatively, rural areas such as Avissawella, Homagama and Padukka due to abundance of bare lands, even though there are a lot of developments are going on in these areas.

Table 3. Change of Urban Space.

\begin{tabular}{ccccc}
\hline DSD & $\begin{array}{c}\text { Green Space } \\
\text { in } \mathbf{2 0 0 8}\left(\mathbf{k m}^{2}\right)\end{array}$ & $\begin{array}{c}\text { Green Space } \\
\text { in } \mathbf{2 0 1 5}\left(\mathbf{k m}^{2}\right)\end{array}$ & $\begin{array}{c}\text { Change } \\
\mathbf{( k m}^{\mathbf{2}}\end{array}$ & $\begin{array}{c}\text { Percentage } \\
\text { Change }\end{array}$ \\
\hline Colombo & 5.740 & 4.383 & -1.357 & 23.64 \\
Dehiwala & 5.767 & 3.548 & -2.219 & 38.48 \\
Avissawella & 145.032 & 143.386 & -1.646 & 1.13 \\
Homagama & 114.298 & 113.265 & -1.033 & 0.90 \\
Kaduwela & 81.955 & 76.111 & -5.844 & 7.13 \\
Kesbewa & 58.831 & 55.247 & -3.584 & 6.09 \\
Kolonnawa & 24.268 & 20.726 & -3.542 & 14.60 \\
Maharagama & 35.649 & 31.802 & -3.847 & 10.79 \\
Moratuwa & 14.119 & 9.389 & -4.730 & 33.50 \\
Padukka & 105.501 & 104.997 & -0.504 & 0.48 \\
Rathmalana & 10.321 & 7.038 & -3.283 & 31.81 \\
Kotte & 13.981 & 11.122 & -2.859 & 20.45 \\
Thimbirigasyaya & 13.638 & 10.146 & -3.492 & 25.60 \\
TOTAL & $\mathbf{6 2 9 . 1 0 0}$ & $\mathbf{5 9 1 . 1 6 0}$ & -37.94 & $\mathbf{6 . 0 3}$ \\
\hline
\end{tabular}

It was determined the changes of other two land use classes as well in the study. According to the Table 4, it clearly shows the area of soil/building/road land use class has dramatically increased by $34.375 \mathrm{~km}^{2}$ in 2015 with a rate of $73.79 \%$ compared to 2008 due to development projects, specially, in Kaduwela, Moratuwa and Maharagama divisions except Padukka. During this period, the government was given more priority for road development projects. Therefore, in the areas such as Kaduwela, Kesbewa and Maharagama, the rate of change is very significant. According to the Table 
3 and Table 4, the highest green space reduction of $5.844 \mathrm{~km}^{2}$ and the highest soil/building/road increment of $4.767 \mathrm{~km}^{2}$ can be seen in Kaduwela DS Division.

Table 4. Changes of Soil/ Building/ Road Extents.

\begin{tabular}{ccccc}
\hline DSD & $\begin{array}{c}\text { Soil/ Building/ } \\
\text { Road in 2008 } \\
\left(\mathrm{km}^{2}\right)\end{array}$ & $\begin{array}{c}\text { Soil/ Building/ } \\
\text { Road in 2015 } \\
\left(\mathrm{km}^{2}\right)\end{array}$ & $\begin{array}{c}\text { Change } \\
\left(\mathrm{km}^{2}\right)\end{array}$ & $\begin{array}{c}\text { Percentage } \\
\text { Change }\end{array}$ \\
\hline Colombo & 11.149 & 12.701 & +1.552 & 13.92 \\
Dehiwala & 2.264 & 4.441 & +2.177 & 96.16 \\
Avissawella & 1.347 & 2.374 & +1.027 & 76.24 \\
Homagama & 3.340 & 4.267 & +0.927 & 27.75 \\
Kaduwela & 3.203 & 7.970 & +4.767 & 148.83 \\
Kesbewa & 1.938 & 5.094 & +3.156 & 162.85 \\
Kolonnawa & 2.680 & 5.980 & +3.300 & 123.13 \\
Maharagama & 1.340 & 5.025 & +3.685 & 275.00 \\
Moratuwa & 3.764 & 8.276 & +4.512 & 119.87 \\
Padukka & 1.377 & 1.245 & -0.132 & -9.59 \\
Rathmalana & 2.759 & 5.953 & +3.194 & 115.77 \\
Kotte & 2.091 & 4.871 & +2.780 & 132.95 \\
Thimbirigasyaya & 9.333 & 12.763 & +3.430 & 36.75 \\
TOTAL & 46.585 & $\mathbf{8 0 . 9 6 0}$ & +34.375 & 73.79 \\
\hline
\end{tabular}

In contrast, the area covered by water has not change a lot, but it has been increased by approximately $1.173 \mathrm{~km}^{2}$ with a rate of $13.6 \%$ (Table 5). But in this regard, it can see a lot of unexpected rate of changes in, specially, Dehiwala, Maharagama, Padukka and Thimbirigasyaya DSDs, since the images have been taken in two different dates (one is in November and other one is in April) in two years.

Table 5. Change of water areas.

\begin{tabular}{ccccc}
\hline DSD & $\begin{array}{c}\text { Water areas in } \\
2008\left(\mathrm{~km}^{2}\right)\end{array}$ & $\begin{array}{c}\text { Water areas in } \\
2015\left(\mathrm{~km}^{2}\right)\end{array}$ & $\begin{array}{c}\text { Change } \\
\left(\mathrm{km}^{2}\right)\end{array}$ & $\begin{array}{c}\text { Percentage } \\
\text { Change }\end{array}$ \\
\hline Colombo & 0.733 & 0.538 & -0.195 & -26.60 \\
Dehiwala & 0.018 & 0.060 & 0.042 & 233.33 \\
Avissawella & 0.707 & 0.827 & 0.120 & 16.97 \\
Homagama & 0.197 & 0.202 & 0.005 & 2.54 \\
Kaduwela & 1.570 & 1.646 & 0.076 & 4.84 \\
Kesbewa & 2.147 & 2.175 & 0.028 & 1.30 \\
Kolonnawa & 0.574 & 0.717 & 0.143 & 24.91 \\
Maharagama & 0.091 & 0.254 & 0.163 & 179.12 \\
Moratuwa & 2.033 & 2.051 & 0.018 & 0.89 \\
Padukka & 0.005 & 0.640 & 0.635 & 12700.00 \\
Rathmalana & 0.097 & 0.096 & -0.001 & -1.03 \\
Kotte & 0.427 & 0.505 & 0.078 & 18.27 \\
Thimbirigasyaya & 0.024 & 0.085 & 0.061 & 254.17 \\
TOTAL & $\mathbf{8 . 6 2 3}$ & $\mathbf{9 . 7 9 6}$ & $\mathbf{1 . 1 7 3}$ & $\mathbf{1 3 . 6 0}$ \\
\hline
\end{tabular}

As the final task of the study which is the main objective, per capita green spaces of every DSD were calculated using the population data and resulted green space extents for each year. When entire 
Colombo district is considered the per capita green spaces were $272.361 \mathrm{~m}^{2}$ and $248.811 \mathrm{~m}^{2}$ in 2008 and 2015 respectively. It means that, as a whole, Colombo district is in the safer side, even though there is a gradual decrease. But when the data were analyzed DSD wise, Colombo DSD, the area which contains a lot of human interactions, does not comply with either EU or UN standards for per capita green space. As shown in Table 6, it can be observed that the highest (68.19\%) and lowest $(4.466 \%)$ rates of reductions of per capita green space are recorded by Hanwella DSD and Colombo DSD respectively. Additionally, the rates of the reduction of the areas such as Padukka, Kaduwela, Moratuwa and Rathmalana are considerable. Further it can be noticed that the values of Dehiwala and Thimbirigasyaya DSDs are getting closer to the minimum bounds of EU and UN standards.

Table 6. Per Capita Green Spaces in 2008, 2015 and 2025 (predicted)

\begin{tabular}{ccccc}
\hline DSD & $\begin{array}{c}\text { Per Capita } \\
\text { Green Space in } \\
\text { Colombo }\end{array}$ & $\begin{array}{c}\text { Per Capita } \\
\text { Green Space in } \\
2015\end{array}$ & $\begin{array}{c}\text { Change } \\
(\%)\end{array}$ & $\begin{array}{c}\text { Predicted Per } \\
\text { Capita Green } \\
\text { Space in 2025 }\end{array}$ \\
\hline Dehiwala & 18.047 & 13.581 & 4.466 & 7.201 \\
Avissawella & 65.661 & 37.829 & 27.832 & -1.931 \\
Homagama & 1278.073 & 1209.883 & 68.190 & 1112.469 \\
Kaduwela & 483.945 & 464.692 & 19.253 & 437.188 \\
Kesbewa & 325.144 & 294.485 & 30.659 & 250.686 \\
Kolonnawa & 141.051 & 219.847 & 21.204 & 189.556 \\
Maharagama & 187.181 & 106.775 & 20.406 & 77.624 \\
Moratuwa & 84.463 & 158.095 & 24.388 & 123.255 \\
Padukka & 1618.926 & 53.942 & 30.524 & 10.336 \\
Rathmalana & 108.454 & 1556.778 & 62.148 & 1467.995 \\
Kotte & 130.051 & 69.249 & 39.205 & 13.242 \\
Thimbirigasyaya & 57.548 & 101.491 & 28.560 & 60.691 \\
\hline
\end{tabular}

As a sub objective of the study, it was determined the predicted per capita green space with the current rate of change of green space and the population growth for 2025 (Table 6). It can be, clearly, noted that the problem would be much severe in 2025, specially, in the DSDs of Colombo, Dehiwala, Moratuwa, Rathmalana and Thimbirigasyaya with the current rate of reduction.

\section{Discussion}

As the main economically potential district in Sri Lanka, due to its location, Colombo district takes the leading role in the development of the country. Even though it is, comparatively, small in size, its location and contribution is very important. According to the findings of the study, it can be noted that Colombo district, as a whole, is currently in the manageable state with a very good rate of per capita green space, since it fulfill the standard rates which were determined by the WHO, UN and EU. But the main hub of the city does not satisfy the EU and UN standards. However, it would be a serious issue in the near future with the current rate, specially, in the main city limits. Therefore, an urgent comprehensive green space plan is required to re-establish the greener, pleasant and comfortable living standards in the city and, specially, its suburbs. In this case, this study is very important to identify the areas to give more priorities to make an environmental friendly country.

The study shows that from the integrated methodology of remote sensing and GIS gives comparably good results in analyzing land cover changes and related works in determining the per capita green space. Study highly recommends that the satellite images taken on the nearly same dates on two years should be used in this type of work. Since Sri Lanka does not suffer seasonal changes, it was not highly influenced on the final results. NDVI differencing technique was used in the study 
to detect the landuse changes in the study area. It can be concluded that NDVI method gives promising results in landuse change detections. Even though the index values represent the health of the green areas, in this study those values were not considered.

The per capita green space explains the environment sustainability of a certain area in a good manner. In this study, it was calculated by taking a DSD as the smallest unit. In this case, it gives a general rate for a division. But, to understand about the problem thoroughly, per capita green space should be calculated either land parcel wise or village wise. For an example, if the rate was calculated village wise in this study, the most of the villages in Colombo DSD would not fulfill the aforesaid standards. Therefore, the study highly recommends calculating the rate by taking smaller sized administrative units.

Additionally as a further study, it suggests to implement a tax system to get the attraction of the general public. In such a system, the government can collect taxes from the land owners who are not maintain or do not fulfill the government standards on per capita green space. At the same time, the government can compensate to those who are maintaining a better rate of per capita green space which is more than the required rate as a reward. This would be a better method to get the maximum support from the public and encourage them to make a greener area.

Authors should discuss the results and how they can be interpreted in perspective of previous studies and of the working hypotheses. The findings and their implications should be discussed in the broadest context possible. Future research directions may also be highlighted.

Conflicts of Interest: The authors declare no conflict of interest. 


\section{References}

1. Blanco, H.; Alberti, M.; Forsyth, A.; Krizek, K.J.; Rodriguez, D.A.; Talen, E. Hot, congested, crowded and diverse: Emerging research agendas in planning. Progress in Planning 2009, Volume 71(4), pp. 153-205.

2. Arabi, Z.; Hatami, D. and Jadidoleslami, M. Analysis of the pattern of spatial-local distribution of green space (Case study of Mehr city in Iran). Indian Journal of Scientific Research 2014, Volume 8(1), pp. 197-202.

3. Hillsdon, M.; Panter, J.; Foster, C. and Jones, A. The relationship between access and quality of urban green space with population physical activity. Public Health 2006, Volume 120, pp. 1127-1132.

4. Ebrahimpour, M.; Saremi, H.R.; Khakpour, B. Analyzing of urban green spaces development process with emphasis on sustainable principles (Case study: Mashhad metropolitan). American Journal of Engineering Research 2013, 2320-0936, 2(4), pp. 113-19.

5. Paquet, C.; Orschulok, T.; Coffee, N.; Howard, N.; Hugo, G.; Taylor, A.; Adams, R. and Daniel, M. Are accessibility and characteristics of public open spaces associated with a better cardio metabolic health? Landscape and Urban Planning 2013, 118, pp. 70-78.

6. Ulrich, R.S. Evidence-based health care architecture. Lancet 2006, 368, pp. S38-S39.

7. Al-Ballaa, H.; Comber, A. and Smith, C. Distribution Pattern Analysis of Green space in Al-Madinah Using GIS, GIS Research UK 20th Annual Conference, Lancaster, United Kingdom, 11-13 ${ }^{\text {th }}$ April 2012, pp. 161169.

8. Mcpherson, E.G. Chicago's urban forest ecosystems. 1994, pp. 23-34.

9. Gupta, K.; Roy, A.; Luthra, K.; Maithani, S. and Mahavir. GIS based analysis for assessing the accessibility at hierarchical levels of urban green spaces. Urban Forestry and Urban Greening 2016, Volume 18 pp. 198211.

10. Laghai, H. and Bahmanpour, H. GIS Application in Urban Green space Per Capita Evaluation. Annals of Biological Research 2012, Volume 3(5), pp. 2439-2446.

11. Khalil, R. Quantitative evaluation of distribution and accessibility of urban green spaces (Case study: City of Jeddah). International Journal of Geomatics and Geosciences 2014, Volume 4(3) pp. 526-535.

12. Department of Census and Statistics Staff. The Report on Mid-year Population Estimates by District \& Sex, 2012 - 2016, Department of Census \& Statistics, Ministry of Policy Planning and Economic Affairs, Sri Lanka 2016.

13. Song, C. and Woodcock, C.E. Monitoring forest succession with multitemporal Landsat images: factors of uncertainty. IEEE Transactions on Geoscience and Remote Sensing 2003, Volume 41 pp. 2557-2567.

14. Singh, A. Review Article Digital change detection techniques using remotely-sensed data. International Journal of Remote Sensing 1989, Volume 10(6) pp. 989-1003.

15. Im, J.; Rhee, J.; Jensen, J.R. and Hodgson, M.E. An automated binary change detection model using a calibration approach. Remote Sensing of Environment 2007, Volume 106 pp. 89-105.

16. Lu, D.; Mausel, P.; Brondi'zio, E. and Moran, E. Change detection techniques. International Journal of Remote Sensing 2004, Volume 25(12) pp. 2365-2407.

17. Gao, B.C. NDWI - A Normalized Difference Water Index for remote sensing of vegetation liquid water from space. Remote Sens. Environ. 1996, Volume 58 pp. 257-66.

18. Pettorelli, N.; Vik, J.O.; Mysterud, A.; Gaillard, J.M.; Tucker, C.J. and Stenseth, N.C. Using the satellite derived NDVI to assess ecological responses to environmental change. Trends in Ecology and Evolution 2005, Volume 20(9) pp. 503-510.

(C) 2016 by the authors; licensee Preprints, Basel, Switzerland. This article is an open access article distributed under the terms and conditions of the Creative Commons by Attribution (CC-BY) license (http://creativecommons.org/licenses/by/4.0/). 